\title{
Medication errors:
}

\section{prevention using information technology systems}

\section{Abha Agrawal}

Department of Clinical Medicine and Medical Informatics, State University of New York Downstate, Brooklyn, NY, USA

\section{Correspondence}

Professor Abha Agrawal, Department of Clinical Medicine and Medical Informatics, State University of New York Downstate, Brooklyn, NY 11203, USA.

Tel: $+1-718-245-3980$

Fax:+1-718-245-5347

E-mail:agrawal.abha@gmail.com

\section{Keywords}

CPOE, decision support, electronic health record, health information technology, medication errors, patient safety

\section{Received}

9 February 2009

Accepted

18 March 2009

1. Given the high frequency of medication errors with resultant patient harm and cost, their prevention is a worldwide priority for health systems.

2. Systems that use information technology (IT), such as computerized physician order entry, automated dispensing, barcode medication administration, electronic medication reconciliation, and personal health records, are vital components of strategies to prevent medication errors, and a growing body of evidence calls for their widespread implementation.

3. However, important barriers, such as the high costs of such systems, must be addressed through economic incentives and government policies.

4. This paper provides a review of the current state of IT systems in preventing medication errors.

A substantial body of evidence from international literature points to the risks posed by medication errors and the resulting preventable adverse drug effects. In the USA, medication errors are estimated to harm at least 1.5 million patients per year, with about 400000 preventable adverse events [1]. In Australian hospitals about $1 \%$ of all patients suffer an adverse event as a result of a medication error [2]. In the UK, of 1000 consecutive claims reported to the Medical Protection Society from 1 July 1996, 193 were associated with prescribing and medications [3]. Medication errors are also costly - to healthcare systems, to patients and their families, and to clinicians $[4,5]$.

Prevention of medication errors has therefore become a high priority worldwide. There is mounting evidence that systems that use information technology (IT), such as computerized physician order entry, automated dispensing cabinets, bedside bar-coded medication administration, and electronic medication reconciliation, are key components of strategies to prevent medication errors. IT systems have also been reported to have the potential to save up to $\$ 88$ billion over 10 years in costs in the USA, with increasing adoption [6,7]. Hospitals with automated notes and records, order entry, and clinical decision support have fewer complications, lower mortality rates, and lower costs $[8,9]$.

Here I review the current state of various IT systems in preventing medication errors.

\section{The medication management process}

Medication management is a complex, multifaceted operation involving multiple people and numerous steps. Table 1 describes the various steps in a typical medical management process, the estimated error rate for each step, and the 'true' error rate based on the likelihood that the error will be intercepted [10-12]. Since medication administration is the last step in the process, the intercept rate is understandably very low. The last column in Table 1 lists the IT systems that target each step in the process. Many institutions are now implementing a 'closed-loop' system, i.e. end-to-end electronic medication management with seamless flow of information along the process.

\section{Information technology systems in medication management}

Clinical decision making is a complex process that depends on human ability to provide undivided attention and to memorize, recall, and synthesize huge amounts of data - all vulnerable areas. IT systems can improve access to pieces of information, organize them, and identify links between them. Clinicians often 'know' the information (such as a patient's allergies, a drug recall warning, or a 


\section{Table 1}

Steps, error rates, and IT systems in medication management

\begin{tabular}{|c|c|c|c|c|}
\hline Stage & Error rate, \% & Intercept rate, \% & True error rate, $\%$ & Relevant IT systems \\
\hline Dispensing & 11 & 34 & 10 & Robots, automated dispensing cabinets \\
\hline Administration & 38 & 2 & 51 & Bar-coding, electronic medication administration \\
\hline
\end{tabular}

CPOE, computerized physician order entry.

drug-drug interaction) but forget to consider it at the time of prescribing. IT systems are effective in bridging this 'knowing-doing' gap [13], by presenting the relevant information to the clinician at the time of decision making.

\section{Computerized physician order entry with decision support}

Since most errors occur at the prescribing step, computerized physician order entry (CPOE) with patient-specific decision support is a potentially powerful intervention for improving patient safety. Common prescribing errors include using the wrong drug or dosage form, incorrect dose calculation, not checking for allergies, and failure to adjust dosages in patients with renal or hepatic dysfunction [14]. CPOE systems work by (i) making sure that the order is legible and complete, including all necessary information, such as dose, route, and dosage form; (ii) checking for problems such as drug allergies and drug-drug interactions; (iii) providing dosage adjustment calculations based on clinical features such as weight or renal function; (iv) checking for appropriate baseline laboratory results, such as platelet count and international normalized ratio for patients receiving anticoagulants; (v) computing druglaboratory interactions, such as alerting the prescriber to a low potassium concentration when digoxin is being prescribed; and (vi) updating the prescriber with the latest drug information, such as the need to avoid rofecoxib after it had been withdrawn by the manufacturer.

Figure 1 shows a variety of decision support alerts embedded in an intravenous heparin prescribing screen.

Of the various systems used in the medication process, CPOE systems have the largest impact on reducing medication errors, with reported error reductions of $55-83 \%$ $[15,16]$. Other studies have shown impressive reductions in antibacterial drug-related adverse events [17], reduced lengths of stay [18], and improved dosaging of psychoactive drugs in elderly people [19].

\section{Pharmacy dispensing systems}

With the high volume of medications dispensed in hospitals, dispensing errors are common, often go undetected, and can have serious consequences [20]. For example, it has been estimated that $>44000$ errors occur annually in a 735-bed hospital dispensing 6 million doses per year [21]. A variety of systems, such as drug-dispensing robots and automated dispensing cabinets, reduce dispensing errors by packaging, dispensing, and recognizing medications using bar codes $[22,23]$. In a recent evaluation of the impact of bar-coding drugs in pharmacy and checking them before they are sent to patient care units, the dispensing error rate fell by $31 \%$ after bar-code implementation in pharmacy, and the potential rate of adverse events fell by $63 \%[24]$.

\section{Bar-coded medication administration}

Bar-coded medication administration (BCMA) systems require that the nurse who administers the medication at the bedside should scan the patient's identification bracelet and the unit dose of the medication being administered. The system alerts the nurse to any mismatch of patient identity or of the name, dose, or route of administration of the medication. BCMA reduces medication errors by ensuring the five 'rights' of medication administration: the right patient, drug, dose, route, and time. BCMA systems reportedly produce $54-87 \%$ reductions in errors during administration of medications [25]. In a London teaching hospital, implementation of a 'closed-loop' system including CPOE and BCMA reduced prescribing and medication administration errors [26]. BCMA is reviewed in more detail elsewhere in this special issue [27].

\section{Electronic medication reconciliation}

With growing recognition that many inpatient medication errors occur at care transition points, reconciliation of medication lists during admission, transfer and discharge is an important step in improving safety. CPOE systems are effective in reducing errors during prescribing; however, a CPOE system cannot detect an error if the physician does not remember to prescribe a medication that the patient 


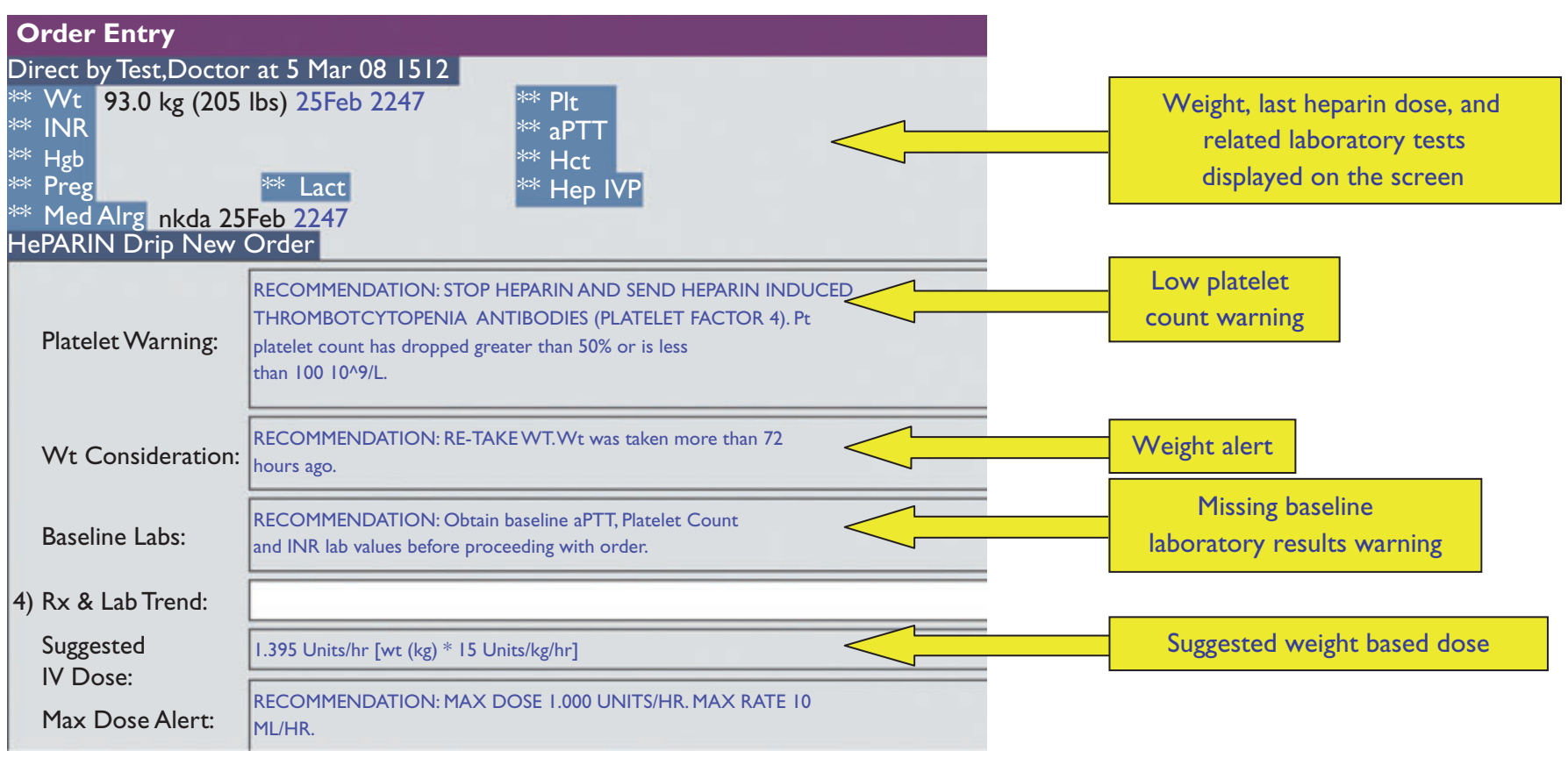

\section{Figure 1}

An example of decision support alerts embedded in the prescribing (order entry) screen for intravenous heparin

was taking at home. There is preliminary evidence that electronic medication reconciliation systems are quite effective in reducing such unintended discrepancies [28].

\section{Personal health records}

Personal health records (PHR) engage and empower patients in their own medical care. An individual can maintain a paper-based record, but in the current context a PHR is defined as 'a set of computer-based tools that allow people to access and coordinate their lifelong health information and make appropriate parts of it available to those who need it' [29]. Implementation of such a record may consist of a 'stand-alone' website for patients to enter their medical data, or a physician/hospital-hosted patient portal, giving patients access to their electronic health record (EHR), or an employer/payer portal giving patients access to claims data.

Online medication lists are an essential component of most PHRs. Patients can access medication information from multiple providers, reconcile them, update them, and share them with their physician. A patient-initiated medication reconciliation system is likely to be more accurate, as patients know not only what has been prescribed but what they are actually taking. Furthermore, advanced PHRs provide decision support tools, such as checking for drug allergies and drug-drug interactions and allowing patients to anticipate potential medication errors and alert physi- cians to them. Since this is an emerging area in health IT, there is no hard evidence as yet; however, there is much optimism about its potential effectiveness in reducing medication errors [30].

\section{Decision support to reduce medication errors of omission}

We often focus on the role of IT in preventing errors of commission (e.g. the wrong dose, route, medication). However, medication errors of omission can have an equally significant impact when evidence of the benefit of the medication is clear [31]. For example, for patients with heart failure due to left ventricular dysfunction, prescription of an angiotensin-converting enzyme inhibitor or angiotensin receptor antagonist is the most useful measure in reducing mortality and rehospitalization in the first 60-90 days after discharge [32]. In a pilot study the implementation of a 'smart' electronic discharge summary that reminds physicians to prescribe these medications improved the prescription rate from 88 to $100 \%$ [33]. Similar systems can be used to remind physicians to prescribe other important medications, such as aspirin or $\beta$-blockers after myocardial infarction.

\section{Concerns and problems}

Although IT systems provide clear and compelling mechanisms for reducing medication errors and improving 
safety, with a significant body of evidence to support their role, there are several concerns about their widespread clinical use.

First, there is scepticism about the evidence regarding the impact of such systems on clinical outcomes. Most of the current evidence is based either on single-site evaluations in large academic hospitals that have developed the systems internally and incrementally [34], or on large-scale economic models relying on projections [35]. The former is limited by questionable generalizability of the findings, as most hospitals will be implementing commercially developed systems with few resources for customization. The latter seem to overstate the potential benefits of IT by making calculations based on best-case scenarios. These problems are being addressed in more recent reports based on rigorous methods demonstrating the positive impact of a number of different IT systems and their clinical implementations, across multiple institutions, on a broad range of clinical outcomes such as inpatient mortality, length of stay, complications, and costs [8].

A second concern is raised by evidence of the potential negative consequences of IT systems on patient safety [36]. IT systems can adversely affect clinical care by generating more work or new work for clinicians, causing workflow problems, or even generating new kinds of errors [37]. These cautionary reports underscore the fact that IT systems must be designed to optimize clinical workflow and must be continually improved. One approach to addressing this problem is to require that clinical IT systems in the market place be tested and approved by a certification agency, such as the Certification Commission for Healthcare Information Technology (CCHIT - http:// www.cchit.org) in the USA. This certification process assures a buyer that a system meets minimum standards in the domains of functionality, interoperability, and privacy and security. Although voluntary, this is similar to approval of medications by the US Food and Drug Administration (FDA), screening out grossly harmful products. Even so, all drugs by the approved FDA still carry risks of potentially harmful effects, especially if they are used inappropriately.

Third, it is being increasingly recognized that to prevent medication errors it is not merely the IT system itself that is important, but its implementation, in other words how it has been incorporated into clinical processes and workflow and how users actually use it in routine clinical care, sometimes described as the sociotechnical environment of the clinical workplace. For example, in one study there was a threefold increase in mortality in children after implementation of CPOE [38]. However, in another study there was a $36 \%$ reduction in standardized mortality using exactly the same software but with a different implementation strategy [39]. The current approach to IT standardization and certification is focused on the functionality of the system, but does not address its implementation or usability by clinicians.
IT systems must be widely implemented for most patients to derive benefits. However, currently only $10 \%$ of US hospitals use CPOE and $<25 \%$ of US physicians in office practices use EHRs [40]. The main barriers to widespread adoption are the high costs of the systems and an environment of misaligned incentives, in which hospitals and physicians pay for the systems, but the insurance companies reap greater financial benefits. One important mechanism to remove this hurdle is through financial incentives to healthcare organizations. The Obama Administration has already proposed incentive payments to Medicare and Medicaid providers and hospitals for using CCHIT-certified EHRs in the widely anticipated 2009 economic stimulus bill. For years, US federal law, commonly called the Stark law, made it illegal for hospitals to assist outside physicians financially in acquiring EHRs. Recently, these restrictions have been significantly softened, removing an important legal barrier from financial incentives for the adoption of such records [41].

\section{Conclusion}

IT systems are key components of a multifaceted strategy to prevent medication errors and improve patient safety. However, we need to be mindful of their potential to affect clinical workflow adversely, with attendant complications. Improving standardization and certification of the design and implementation of such systems should help. In addition, creating an economic and policy environment conducive to the financial goals of hospitals and physicians will facilitate wider adoption.

\section{Competing interests}

None to declare.

\section{REFERENCES}

1 Aspden P, Institute of Medicine (US). Committee on Identifying and Preventing Medication Errors. Preventing Medication Errors. Washington DC: National Academies Press, 2006.

2 Runciman W, Roughhead E, Semple S, Adams R. Adverse drug events and medication errors in Australia. Int J Qual Healthcare 2003; 15 (Suppl.): i49-59.

3 Chief Pharmaceutical Officer. Building a Safer NHS for Patients. Improving Medication Safety. London: Department of Health, 2004. Available at http://www.dh.gov.uk/en/ Publicationsandstatistics/Publications/ PublicationsPolicyAndGuidance/DH_4071443 (last accessed 9 February 2009). 
4 Bates DW, Spell N, Cullen DJ, Burdick E, Laird N, Petersen LA, Small SD, Sweitzer BJ, Leape LL. The costs of adverse drug events in hospitalized patients. Adverse Drug Events Prevention Study Group. JAMA 1997; 277: 307-11.

5 Vincent C, Neale G, Woloshynowych M. Adverse events in British hospitals: preliminary retrospective record review. BMJ 2001; 322: 517-9.

6 Mongan JJ, Ferris TG, Lee TH. Options for slowing the growth of health care costs. N Engl J Med 2008; 358: 1509-14.

7 Hillestad R, Bigelow J, Bower A, Girosi F, Meili R, Scoville R, Taylor R. Can electronic medical record systems transform health care? Potential health benefits, savings, and costs. Health Aff (Millwood) 2005; 24: 1103-17.

8 Amarasingham R, Plantinga L, Diener-West M, Gaskin DJ, Powe NR. Clinical information technologies and inpatient outcomes: a multiple hospital study. Arch Intern Med 2009; 169: 108-14.

9 Jha AK, Orav EJ, Ridgway AB, Zheng J, Epstein AM. Does the Leapfrog program help identify high-quality hospitals? Jt Comm J Qual Patient Saf 2008; 34: 318-25.

10 Bates DW, Cullen DJ, Laird N, Petersen LA, Small SD, Servi D, Laffel G, Sweitzer BJ, Shea BF, Hallisey R. Incidence of adverse drug events and potential adverse drug events. Implications for prevention. ADE Prevention Study Group. JAMA 1995; 274: 29-34.

11 Leape LL, Bates DW, Cullen DJ, Cooper J, Demonaco HJ, Gallivan T, Hallisey R, Ives J, Laird N, Laffel G. Systems analysis of adverse drug events. ADE prevention study group. JAMA $1995 ; 274: 35-43$.

12 California Institute for Health Systems Performance. A compendium of suggested practices for preventing and reducing medication errors. 2001. Available at http://www. chcf.org/topics/hospitals/index.cfm?itemID=19725 (last accessed 9 February 2009).

13 Pfeffer J, Sutton RI. The Knowing-doing Gap. How Smart Companies Turn Knowledge into Action. Boston, MA: Harvard Business School Press, 2000.

14 Lesar TS, Briceland L, Stein DS. Factors related to errors in medication prescribing. JAMA 1997; 277: 312-7.

15 Bates DW, Leape LL, Cullen DJ, Laird N, Petersen LA, Teich JM, Burdick E, Hickey M, Kleefield S, Shea B, Vander Vliet M, Seger DL. Effect of computerized physician order entry and a team intervention on prevention of serious medication errors. JAMA 1998; 280: 1311-6.

16 Bates DW, Teich JM, Lee J, Seger D, Kuperman GJ, Ma'Luf N, Boyle D, Leape L. The impact of computerized physician order entry on medication error prevention. J Am Med Inform Assoc 1999; 6: 313-21.

17 Evans RS, Pestotnik SL, Classen DC, Clemmer TP, Weaver LK, Orme JF Jr, Lloyd JF, Burke JP. A computer-assisted management program for antibiotics and other antiinfective agents. N Engl J Med 1998; 338: 232-8.

18 Chertow GM, Lee J, Kuperman GJ, Burdick E, Horsky J, Seger DL, Lee R, Mekala A, Song J, Komaroff AL, Bates DW.
Guided medication dosing for inpatients with renal insufficiency. JAMA 2001; 286: 2839-44.

19 Peterson JF, Kuperman GJ, Shek C, Patel M, Avorn J, Bates DW. Guided prescription of psychotropic medications for geriatric inpatients. Arch Intern Med 2005; 165: 802-7.

20 Simpson KR. Medication safety with heparin. MCN Am J Matern Child Nurs 2008; 33: 135.

21 Cina JL, Gandhi TK, Churchill W, Fanikos J, McCrea M, Mitton P, Rothschild JM, Featherstone E, Keohane C, Bates DW, Poon EG. How many hospital pharmacy medication dispensing errors go undetected? Jt Comm J Qual Patient Saf 2006; 32: 73-80.

22 Weaver P. Random sampling for quality assurance of the RxOBOT dispensing system. American Society of Health Systems Pharmacists Mid-Year Clinical Meeting, Las Vegas, Nevada, 1998.

23 Jerrard J. Robot PharmD. Drug dispensing robots drastically decrease medication errors. Hospitalist 2006; 24.

24 Poon EG, Cina JL, Churchill W, Patel N, Featherstone E, Rothschild JM, Keohane CA, Whittemore AD, Bates DW, Gandhi TK. Medication dispensing errors and potential adverse drug events before and after implementing bar code technology in the pharmacy. Ann Intern Med 2006; 145: 426-34.

25 AMIA Podcast. Bar Code Medication Administration Evidence. 2007. Available at http://www.amia.org/podcasts (last accessed 7 February 2009).

26 Franklin BD, O'Grady K, Donyai P, Jacklin A, Barber N. The impact of a closed-loop electronic prescribing and administration system on prescribing errors, administration errors and staff time: a before-and-after study. Qual Saf Health Care 2007; 16: 279-84.

27 Cheung K-C, Bouvy ML, De Smet PAGM. Medication errors: the importance of safe dispensing. Br J Clin Pharmacol 2009; 67: 676-80.

28 Agrawal A, Wu W. Reducing medication errors and improving systems reliability using an electronic medication reconciliation system. Jt Comm J Qual Patient Saf 2009; 35: 106-14.

29 Markle Foundation. Connecting for Health. A Public-Private Collaborative. Final Report. 1 July 2003. Available at http://www.connectingforhealth.org/resources/final_ phwg_report1.pdf (last accessed 9 February 2009).

30 Pagilari C, Detmer D, Singleton P. Potential of electronic personal health records. BMJ 2007; 335: 330-3.

31 Hayward RA, Asch SM, Hogan MM, Hofer TP, Kerr EA. Sins of omission: getting too little medical care may be the greatest threat to patient safety. J Gen Intern Med 2005; 20: 686-91.

32 Fonarow GC, Abraham WT, Albert NM, Stough WG, Gheorghiade M, Greenberg BH, O'Connor CM, Pieper K, Sun JL, Yancy C, Young JB; OPTIMIZE-HF Investigators and Hospitals. Association between performance measures and clinical outcomes for patients hospitalized with heart failure. JAMA 2007; 297: 61-70. 
33 Agrawal A, Khaneja M, Onyebuke I. 'Smart' electronic discharge summary to improve care of heart failure patients at discharge. Annual Symposium on Health Care Services in New York. Research and Practice. New York, 2007.

34 Chaudhry B, Wang J, Wu S, Maglione M, Mojica W, Roth E, Morton SC, Shekelle PG. Systematic review: impact of health information technology on quality, efficiency, and costs of medical care. Ann Intern Med 2006; 144: 742-52.

35 Walker J, Pan E, Johnston D, Adler-Milstein J, Bates DW, Middleton $B$. The value of health care information exchange and interoperability. Health Aff (Millwood) 2005; (Suppl. Web Exclusives): W5-10-W5-18.

36 Koppel R, Metlay JP, Cohen A, Abaluck B, Localio AR, Kimmel SE, Strom BL. Role of computerized physician order entry systems in facilitating medication errors. JAMA 2005; 293: 1197-203.

37 Ash JS, Berg M, Coiera E. Some unintended consequences of information technology in health care: the nature of patient care information system-related errors. J Am Med Inform Assoc 2004; 11: 104-12.
38 Han YY, Carcillo JA, Venkataraman ST, Clark RS, Watson RS, Nguyen TC, Bayir H, Orr RA. Unexpected increased mortality after implementation of a commercially sold computerized physician order entry system. Pediatrics 2005 ; 116: 1506-12.

39 Del Beccaro MA, Jeffries HE, Eisenberg MA, Harry ED. Computerized provider order entry implementation: no association with increased mortality rates in an intensive care unit. Pediatrics 2006; 118: 290-5.

40 Robert Wood Johnson Foundation. Health Information Technology in the United States: Where We Stand, 2008. Available at http://www.rwjf.org/files/research/062508. hit.exsummary.pdf (last accessed 9 February 2009).

41 Health Information Technology. HIT Certification: Stark and Anti-Kickback in HIT. Available at http://www.hhs.gov/ healthit/certification/stark/ (last accessed 5 February 2009). 